\title{
Termite mound cover and abundance respond to herbivore-mediated biotic changes in an African savanna
}

\author{
Grace Charles ${ }^{1}$, Corinna Riginos ${ }^{2}$, Kari Veblen $^{3}$, Duncan Kimuyu ${ }^{4}$, and Truman Young ${ }^{1}$ \\ ${ }^{1}$ University of California Davis \\ ${ }^{2}$ The Nature Conservancy, \\ ${ }^{3}$ Utah State University \\ ${ }^{4}$ Karatina University
}

January 18, 2021

\begin{abstract}
Both termites and large mammalian herbivores (LMH) are savanna ecosystem engineers that have profound impacts on ecosystem structure and function. Both of these savanna engineers modulate many common and shared dietary resources such as woody and herbaceous plant biomass, yet few studies have addressed how they impact one another. In particular, it is unclear how herbivores may influence the abundance of long-lived termite mounds via changes in termite dietary resources such as woody and herbaceous biomass. While it has long been assumed that abundance and areal cover of termite mounds in the landscape remains relatively stable, most data are observational, and few experiments have tested how termite mound patterns may respond to biotic factors such as changes in large herbivore communities. Here, we use a broad tree density gradient and two landscape-scale experimental manipulations - the first a multi-guild large herbivore exclosure experiment and the second a tree removal experiment- to demonstrate that patterns in termite mound abundance and cover are unexpectedly dynamic. Termite mound abundance, but not areal cover not significantly, is positively associated with experimentally controlled presence of cattle, but not wild mesoherbivores (15-1000 kg) or megaherbivores (elephants and giraffes). Herbaceous productivity and tree density, termite dietary resources that significantly affected by different LMH treatments, are both positive predictors of termite mound abundance. Experimental reductions of tree densities are associated with lower abundances of termite mounds. These results reveal a richly interacting web of relationships among multiple savanna ecosystem engineers and suggest that termite mound abundance and areal cover is intimately tied to herbivore-driven resource availability.
\end{abstract}

\section{Hosted file}

Charles Termites Dec 2020.pdf available at https://authorea.com/users/390049/articles/504488termite-mound-cover-and-abundance-respond-to-herbivore-mediated-biotic-changes-in-anafrican-savanna 